\title{
ÉTICA, ORGANIZAÇÃO E VALORES ÉTICO-MORAIS EM CONTEXTO ORGANIZACIONAL
}

\begin{abstract}
Resumo: $O$ artigo tem como objetivo refletir sobre um conjunto de questões éticas, tecendo algumas considerações, que nos permitem perceber como a ética e os princípios a ela associados se envolvem na prática das ações e dos comportamentos humanos nas organizações. Os comportamentos éticos, mas também antiéticos, aparecem em discursos orientados para as relações entre os seus participantes e as consequências para o sucesso ou insucesso das pessoas e das organizações. Cada vez mais se fala de ética, de moral, de cidadania $e$ de valores em todas as organizações sejam elas empresariais, governamentais, de solidariedade social ou outras mas todas com o objetivo da justiça e dos direitos das pessoas. Os fundamentos da ética estão nas pessoas, nos aspetos essenciais da natureza do ser humano, na sua consciência e na dignidade. O texto analisa num primeiro ponto os fundamentos da ética e da organização; o segundo trata a dimensão dos valores ético-morais; o terceiro presta atenção à ética como expressão dos direitos humanos; o quarto diz respeito à forma como percecionamos a construção do discurso em torno da ética e da organização, por fim, o quinto e último ponto procura fazer uma abordagem à importância dos códigos de ética nas organizações. Da revisão sistemática que fizemos da literatura foi possível evidenciar a relevância atribuída à ética quando posta em prática pelos membros das organizações. Os princípios ligados à ética: justiça, honestidade, verdade, respeito, dignidade $e$ os direitos humanos, são violados constantemente pelas organizações com riscos prejudiciais para as pessoas. Ética que não é apenas pessoal mas é sobretudo coletiva. É na senda deste conjunto de questões que sistematizamos alguns desafios éticos que podem contribuir para uma discussão reflexiva dos valores ético-morais em contexto organizacional.
\end{abstract}

Maria Olívia Dias

Palavras-chave: Ética, Organização, Valores, Conduta, Códigos.

\footnotetext{
${ }^{1}$ Docente da Universidade Católica Portuguesa - Centro Regional das Beiras - Pólo de Viseu.profaoliviadias@gmail.com
} 


\title{
ETHICS, ORGANIZATION AND ETHICAL MORAL VALUES IN ORGANIZATIONAL CONTEXT
}

\begin{abstract}
This article reflects over a number of ethical questions, aiming some considerations that allow to understand how ethics and its principles are connected and evolve in the practice of organizational actions and human behaviour. The ethical but also anti-ethical behaviours appear in a guided speech towards relations between participants and consequences to success or failure of people and organizations. More and more we speak of ethics, moral, citizenship and values in all institutions whether they are enterprises, government, social solidarity and others, all aiming for justice and people's rights. The basis for ethics is in people, in their essence nature as human beings, their conscience and dignity. This article analysis at first the grounds for ethics and organizations; second the dimension of ethical-moral values; third ethics as an expression of human rights; fourth the way we see the creation of a speech around ethics and organizations and last, the fifth argument looks to seek for an approach to the importance of ethical codes in organizations. From the systematic review of literature was possible to underline the relevance of ethics when practiced by members of an organization. The principles connected to ethics: justice, honesty, truth, respect, dignity and human rights are often violated by the organizations in prejudice of people. Ethics is not only individual but general. It is in this context of arguments that we compelled that ethical challenges can contribute for a reflexive discussion of ethical-moral values in organizations.
\end{abstract}

Keywords: Ethics, Organization, Values, Conduct, Codes.

\section{INTRODUÇÃO}

\begin{abstract}
Ambos concordamos que o comportamento ético está relacionado com o amor - próprio. Ambos acreditamos que as pessoas que se sentem bem consigo próprias preenchem a condição indispensável para resistir às pressões do exterior e para fazer o que está certo em vez do que é apenas conveniente, popular ou lucrativo. Acreditamos que, em qualquer negócio, uma moral forte é meio caminho andado para o sucesso. Acreditamos que os gestores éticos são os gestores campeões.
\end{abstract}

Kenneth Blanchard e Peace Vicent.

O texto aqui apresentado é constituído a partir de duas realidades, que do nosso ponto de vista não podem ser dissociadas uma da outra, que 
são a ética e a organização. Estes dois conceitos não podem ser vistos exclusivamente como sendo construções teóricas, não são abstrações, são realidades concretas, observadas por todos nós, tornando-se fácil a perceção e a visibilidade dos comportamentos tanto pessoais como coletivos nas organizacionais. Por isso mesmo a conduta ética é o reflexo da conduta de todos os profissionais, fortalecendo as relações interpessoais, o desenvolvimento, o sucesso e a imagem da organização.

A ética é nas palavras de Megale (1989, p.169), o que de mais justo existe. Estas palavras, que são sem dúvida muito fortes, pretendem afirmar dentro do possível, tudo aquilo que move a dinâmica e a justificação na elaboração deste texto.

Por conseguinte, a ética e as organizações, tornam-se indissociáveis estando diretamente ligadas a relações, a comportamentos, que nas ciências sociais, não esquecendo a sua dimensão teórica ou cognitiva, assumem medidas que contemplam as observações empíricas.

Todos sabemos que a literatura tem produzido uma vasta investigação nesta área. Toda esta literatura aponta para uma forma pró ativa da organização, pois procura perceber através dos comportamentos, dos valores, da moral, da consciência ética, quais as formas e as preocupações com a colaboração entre todos os saberes dos participantes, como podem comprometer-se e contribuir para o seu bem-estar, mas também, para o prestígio e o sucesso da organização.

Percebemos então, quando falamos de ética, de valores, de moral nos dias de hoje, sendo apaixonante, não deixa de ser também de grande responsabilidade. Nas considerações defendidas por Banks \& Nohr (2008) é fácil nos tempos que correm onde tudo é materialismo, individualismo que as indiferenças entre as pessoas sejam muitas. Todos somos responsáveis uns pelos outros, isto torna-se evidente quando pensamos a ética como um bem, não exclusivo de uma pessoa, mas das pessoas em sociedade nas suas dimensões práticas, nos seus comprometimentos em relação aos outros.

As ações desenvolvidas nas organizações não podem prescindir dos comportamentos éticos, tanto pessoais como coletivos, sob pena de não cumprirem os seus deveres. A ética é um instrumento de conduta das responsabilidades sociais, das obrigações da organização, para atingir os fins pessoais e coletivos a que se propõe. A ética é um ideal na organização, embora por vezes o ser humano, e porque é humano, percorra caminhos menos éticos e se desvie dos propósitos defendidos pela organização nos seus inícios.

Neste sentido, o nosso principal objetivo reside na análise dos conceitos que estão na base deste artigo dando especial ênfase à ética e à 
importância que esta tem na construção de atitudes e comportamentos éticos e morais, extremamente úteis nas relações pessoais e institucionais.

É assim que Argandoña Ramiz (1994, p.59) concebe a questão da ética como sendo um fenómeno da política, da economia, da empresa organizacional. $\mathrm{O}$ autor sublinha que a ética está na moda pela falta de ética que observamos. Produzir, competir e superar este mercado corrupto, com trabalhadores, diretores, com imoralidade, com vícios, não é tarefa fácil. Também Moreira (1996, p.289) põe em destaque a importância que a ética tem para as pessoas e para as organizações nas sociedades modernas e progressistas onde tudo parece ser normal, o que não é verdade.

Não é por acaso que as grandes épocas de reflexão sobre a ética foram as grandes épocas de transição, em que se verificaram também muitos episódios antiéticos associados à corrupção, a história está cheia desses exemplos. Desaparecem certezas, as pessoas perdiam o rumo e cada qual fazia o que lhes apetecia, defendendo por um lado os interesses privados, e por outro o grupo. Hoje, em termos semelhantes, volta-se a falar de ética exatamente para se encontrarem normas que conduzam a comportamentos cívicos e de cidadania. Atualmente, tanto o mundo como o nosso país parecem estar numa época propícia para voltarmos a falar de ética nas organizações, sejam elas políticas, económicas, ou outras.

Queremos sublinhar, o facto deste campo da ética ser tão vasto, que não cabe na dimensão de um artigo aprofundar toda a riqueza que o envolve, levando-nos a proceder com alguns limites tanto na abrangência como no aprofundamento. É neste quadro de análise que o texto aqui tratado se organiza em cinco partes: na primeira discute-se o conceito e o significado de ética na sua relação com a organização. A segunda analisa os valores-ético morais nas organizações. A terceira parte procura relacionar a ética com os direitos humanos. Por seu turno a complexidade do conjunto organizacional introduz-nos na quarta parte que trata para a construção do discurso sobre a ética nas organizações, abordando de modo específico a exigência da ética como fator relacional e a ética em relação à competitividade. Embora a ética seja única, do ponto de vista teórico e filosófico, do ponto de vista prático cada organização estabelece as regras, as relações, em circunstâncias concretas, conduzindo-nos à quinta e última parte que remete para os códigos de ética nas organizações relevando a sua necessidade e importância pelo facto de as pessoas terem direito a conhecer as normas que têm de cumprir, para que se comportem e responsabilizem conforme as mesmas, reconhecendo os seus direitos, mas exercendo também os seus deveres.

Convém sublinhar, desde já, que a vida em grupo, seja ele qual for, implica que o relacionamento entre as pessoas se paute por regras que permitam evitar e equilibrar eventuais conflitos e harmonizar interesses 
individuais e coletivos (Gil \& Delgado, 1996, p.19). Viver em comunidade requer que os indivíduos não satisfaçam apenas os seus desejos mas que se adaptem a regras, em virtude das quais se torna possível viver em sociedade.

\section{FUNDAMENTOS DA ÉTICA E DA ORGANIZAÇÃO}

\subsection{A Ética e o seu Significado}

Em qualquer dicionário corrente, podemos ver entre outras respostas quando nos questionamos acerca do que é a ética, e encontramos inúmeras definições, "moral", "diferença entre bem e mal", "comportamento bom ou mau", "a ética é a ciência da moral", para citarmos apenas as que nos parecem mais adequadas para a reflexão deste texto. Do nosso ponto de vista, associamos o termo "ética" à ideia de educação, formação humana, caracter das pessoas, desempenho e postura na organização em termos de relacionamento (Ferreira \& Dias, 2005).

É sabido que as definições apenas ajudam a compreender e a preparar o caminho para uma análise de maior aprofundamento. Acrescente-se, no entanto, que o nosso interesse passa por traçar em termos esquemáticos o essencial, sem nos perdermos em grandes considerações. Aludimos a este conceito pela importância e relação que ele tem com o comportamento humano, tendo como principal objetivo dar uma perspetiva mais esclarecedora, o que justifica a sua abordagem.

A ética no seu sentido etimológico é uma palavra que vem do grego ethos e define-se por duas formas (Trigo (1999, p.225; Dias, 2004, p.85). a primeira, êthos", refere-se ao modo de ser, ao carater, à realidade interior donde provêm os atos humanos. a segunda éthos, indica os costumes, os hábitos ou o agir habitual; atos concretos que indicam e realizam o modo de ser da pessoa.

$\mathrm{Na}$ operacionalização deste conceito não se prescinde da moral, não podemos ficar no nível abstrato, é preciso passar à prática da ética. Enfatizando a ligação entre estes dois conceitos, moral e ética, poder-se-á dizer que a moral aparece mais ou menos como institucionalização da ética. Embora a palavra ética e moral remetam para uma mesma realidade, e alguns autores as usem como equivalentes, sendo utilizadas alternadamente (Banks \& Nohr, 2008, p.11; Argandoña, 1994, p.10), a maioria dos dicionários e outros autores apresentam uma certa distinção entre os dois conceitos (Brugger, 1969; Pinto, 1990).

Também estamos deste lado, para nós a distinção entre os dois termos, ética e moral, explica-se pelo facto de que a ética investiga a fundamentação do agir, os princípios e valores, a dimensão da 
interioridade dos atos, aquilo que é mais pessoal. A moral indica ações e normas concretas, ou seja a aplicação das regras que são objeto da ética. Por seu turno, a ética é o modo como determinada pessoa ou sociedade se comportam (Cabral, 2000; Ferreira \& Dias, 2005, p.16-20). A ética estuda o ser e o sentido das normas morais, ou seja, explica o bem moral e as suas características. No fundo, a ética é a ciência da moral e a arte de dirigir a conduta das pessoas.

Se a ética é indissociável da moral, confundindo-se muitas vezes com ela, também outros conceitos estão igualmente ligados, como por exemplo: os valores, os regulamentos, as normas, as leis que regem os comportamentos das pessoas na sociedade e, neste caso, as condutas das pessoas nas organizações. Se a moral significa agir de acordo com os bons costumes, ou a capacidade de distinguirmos entre o bem e o mal, também sabemos que ela é dentro de uma determinada sociedade transmissível no tempo (Banks \& Nohr, 2008).

Ética para os Gregos, significa uma sociedade bem ordenada, uma boa sociedade. Indica os comportamentos que numa sociedade, na sua sabedoria e experiência, considera positivos para a ordem social, para o progresso e o aumento do bem-estar de todos. Tais comportamentos são precisamente "éticos" ou seja, eticamente honestos (Martini, 1993, p.9). A palavra ética é usada em sentido absoluto, isto é: ético não é apenas aquilo que se costuma fazer numa sociedade identificada como boa, mas sobretudo aquilo que é bom em si mesmo; o que deve ser feito ou evitado, independentemente das vantagens pessoais, organizacionais ou sociais que daí possam advir, o que é digno do Homem, ou o que se lhe opõe, o que não se pode discutir nem transigir (Martini, p.10,11).

Podemos fazer uma reflexão da ética mais filosófica sobre os comportamentos humanos e sobre o sentido último, onde a existência de condutas superiores não tem preço porque ultrapassa o prazer, o lucro e o interesse de qualquer motivação. Podemos então dizer com Trigo (1999, p.267) que a ética é o estudo filosófico, explicativo dos factos morais, os quais são apreciações éticas, preceitos, normas, atitudes e manifestações de consciência.

Depois desta reflexão torna-se relevante afirmar que os objetos da ética são os atos humanos, não apenas na sua descrição, mas na explicação e valorização do comportamento. Deste modo, não podemos ignorar como vem assinalado, pelos autores Rego, Moreira e Sarrico (2003), que a ética tem sempre no centro a pessoa humana, a sua dignidade e igualdade fundamentais, o seu direito à realização e à felicidade, na sua vocação pessoal, organizacional e comunitária. Percebemos assim, as razões pelas quais a ética se tornou uma questão central, do nosso tempo, mas também condição do futuro para as pessoas, 
para a organização e para a sociedade concreta, construída na base destes princípios e valores.

\subsection{Relação da Ética com a Organização}

Sem nos perdermos em grandes considerações, com o conceito de organização, embora seja para nós apaixonante, pela sua dinâmica interna e externa, relações e composição, isto é, todo o conjunto organizacional na sua complexidade, como nós o definimos em Sociologia das Organizações, achamos que seja útil a sua análise sobretudo para o leitor menos familiarizado com ele. Se a relacionamos com a ética é preciso entendermos o que é, tendo em conta a sua base, ou seja, as pessoas e a coletividade como um fenómeno total, visto como conjunto organizacional complexo.

De acordo com a literatura existente podemos resumir a definição de organização do ponto de vista da origem do seguinte modo: a organização tem origem no Grego "Organon", que significa instrumento, utensílio, órgão, ou aquilo com que se trabalha (significados, sd).

No que se refere à noção de organização assume dois significados: o primeiro designa unidades e entidades sociais, conjuntos práticos, como por exemplo bancos, fábricas, administração pública, escolas, hospitais, prisões, instituições de solidariedade social, etc. $\mathrm{O}$ segundo evidencia a organização como estrutura de realização de objetivos ou metas a atingir. É mais uma perspetiva instrumental das organizações.

Assim, na primeira noção a organização é uma entidade social, conscientemente coordenada e controlada, gozando de fronteiras delimitadas, que funcionam numa base relativamente contínua, tendo em vista a realização de determinados objetivos. A segunda designa certas condutas e processos sociais: ato de organizar tais atividades, a disposição de meios relativamente aos fins e a integração dos diversos membros numa unidade coerente (Nunes, 2007; Bilhim, 1996; Guedes, 2009).

No entendimento do duplo significado, temos um processo orgânico e um processo organizativo. Primeiro a organização vem entendida como um sistema complexo, onde os membros se encontram em interação, onde a mudança num dos componentes provoca impacto nos outros. Isto define a organização como interdependência. Segundo a organização pode ser entendida como gestão do trabalho, ou seja, organizar a organização que pode ser mais ou menos intensa e dificultada dependendo do tipo de organização e da sua complexidade no que diz respeito à estrutura hierárquica, composição, planeamento, condução das tarefas e interatividade da organização com o meio social. $\mathrm{O}$ funcionamento de 
uma organização depende da capacidade de resposta e da interação destes elementos assim como da eficácia da envolvência dos seus membros nas atividades da organização.

A base de qualquer organização são as pessoas cujas capacidades intelectuais lhe permitem seguir modelos de pensamento, mas também de comportamento. No entanto, estão sujeitas a influências que podem vir de diversos ambientes tanto de dentro como de fora da organização. Por isso, as experiências que podem ser boas ou más, os sucessos e insucessos, conhecimentos que se interiorizaram, e continuam a interiorizar, determinam os comportamentos que podem ser identificados como éticos ou antiéticos.

Quanto mais complexas são as organizações, mais difícil se torna a sua organização e mais afastadas são as relações, existindo uma maior necessidade de regras claras e objetivas (Amblard, 1996; Etzioni, 1994; Moreira, 1999 \& Décio, 2002). Sente-se, cada vez mais, a necessidade baseada numa organização que seja vista como uma coletividade, havendo a preocupação não só nas alterações das relações laborais, mas também, nos valores e atitudes do conjunto dos participantes na organização. Portanto, são também a interação entre as pessoas, os grupos, interação com outras organizações e com todo o ambiente.

Neste contexto, torna-se oportuno enquadrar o conceito de organização, potenciando a sua ligação com a ética, associada aos comportamentos das pessoas, torna-se fundamental consolidar a prática da ética nas organizações.

Nesta perspetiva a ética nas organizações remete para os deveres relacionados com a responsabilidade que cada membro da organização tem no seu trabalho. Não ter uma atitude ética é ir contra os deveres profissionais, é não cumprir compromissos assumidos, por escrito ou verbalmente, perante as suas funções e estatutos nas organizações (Ferreira \& Dias, 2005, p.25). A organização não é uma abstração, é uma estrutura física e são as pessoas concretas, é também por isso que a ética se prende com comportamentos concretos.

Parece-nos que estas considerações, sobre a ética em relação com a organização, demonstram bem o sentido de que as organizações são muito mais do que simples recursos financeiros ou equipamentos. As organizações além de uma estrutura física e financeira são também compostas por estruturas ou sistemas humanos, o que exige a integração de pessoas diferentes, com uma vida própria. Esta observância obriga a uma integração harmoniosa de todos os seus membros com objetivos de sucesso das organizações. É nesta perspetiva que entendemos o fenómeno da interdependência entre uma organização e a ética, no seu sentido mais significativo, tanto para a dignidade das pessoas como para o sucesso da 
organização. Este reconhecimento justifica a análise, o enquadramento e a relação entre estes dois conceitos que são a ética e a organização.

Podemos concluir, sem alguma dificuldade, que uma organização é um sistema complexo, onde as pessoas são o centro, por isso os seus métodos e as suas dinâmicas devem ser baseadas na multidisciplinaridade e interdisciplinaridade, as suas prioridades devem estar sempre nas pessoas. A ética é condição necessária nas relações interpessoais, o que só é possível quando há confiança entre as pessoas que direta ou indiretamente estão relacionadas com a organização.

\section{VALORES ÉTICO-MORAIS NAS ORGANIZAÇÕES}

O envolvimento das pessoas nas organizações é impossível sem uma ética de responsabilidade individual e coletiva, apoiada na moral e nos valores defendidos pelas regras universais. As funções e os papéis das pessoas nas organizações tornam-se efetivas quando todos se envolvem no seu conjunto, pondo de parte o individualismo, os interesses pessoais e se adotam comportamentos éticos em consonância com os valores presentes nas realidades que as integram.

Os valores associados à ética exigem critérios de coerência, empenhamento, comprometimento e verdade na e com a organização. Os valores são indispensáveis para o desenvolvimento e a confiança entre todos os participantes da organização, cada um sabe qual a sua posição e por isso havendo a obrigação de se comportar conforme as funções e os papéis que possui na estrutura da organização (Rego, 2000). Quanto mais altas as posições na hierarquia da organização, maior é a responsabilidade destas pessoas, maior atenção devem prestar aos valores e aos comportamentos éticos, pois o exemplo é mais forte do que as palavras por mais corretas que elas sejam têm pouco efeito, quanto muito tornamse inúteis.

Por conseguinte, a ética tem sempre forte ligação aos valores considerados como exemplares no envolvimento globalizado da organização (Pinto, 2003). Neste sentido a ética é cada vez mais pensada, quando o fenómeno organizacional é analisado, tendo merecido uma crescente e especial atenção por escolas e autores que estudam estas matérias. Neste entendimento os valores não são uma opção, são sim uma necessidade sentida pelas pessoas, assim como também a ética. Podemos afirmar que ninguém pode viver bem e feliz quando tanto os valores como a ética são postos em causa através de qualquer método não aceite universalmente.

A ética tem como objetivo integrar de forma harmoniosa os recursos humanos, técnicos e financeiros, de modo a otimizar os valores pessoais e 
sociais da e na organização. De facto, a ética é a base de toda a atividade seja ela económica, política ou social. A ética e a moral são um exercício nos negócios, os valores sustentam o envolvimento das relações nas organizações onde as responsabilidades se distribuem em função do lugar que ocupam. A conduta de um chefe, diretor ou responsável é muito maior que aquela de um subordinado. É por isso que os critérios nas suas eleições ou nomeações não devem por em causa a organização. Estudos sobre a ética (Moreira, 1996a) revelam que por vezes os chefes são escolhidos por favores, amizades, interesses particulares e menos competência científica ou humana. Ora isto não dignifica em nada as pessoas nem as organizações.

Os defensores e preocupados com os valores, com a ética e a moral, adotam atitudes que se identificam com a dignidade humana, assumem a responsabilidade das suas ações. Estes comportamentos respeitam os valores dos outros, aplicam o humanismo, há um envolvimento em causas coletivas dando respostas aos apelos individuais nas organizações mas também na comunidade. De facto, a ética e os valores, nas sociedades atuais, exigem muito no seu seguimento, porém dão um conforto considerável, uma tranquilidade, às pessoas que investem em pô-los em prática.

Destas considerações é fácil ficarmos com a perceção de que a ética é um fator relacional, pois refere-se a pessoas que não são coisas, não são instrumentos da organização, são seres humanos, e por isso devem ser tratadas como tal. Neste entendimento, a prioridade deve ser colocada no SER e não no TER (Banks \& Nohr, 2008, p.20). Sem dúvida, pelos aspetos que já abordamos, nos dias de hoje, estamos mais preparados para TER e menos para o SER. Todos estamos de acordo que há uma crise de ética de valores morais em muitas organizações, mas podemos perguntar o que fazer para que isto não aconteça? Poderemos questionar-nos da nossa sensibilidade sobre a realidade, encontraremos muitas razões, no entanto, e porque a nossa vida que é comandada por valores, deve trabalhar em função de uma conduta aceite e reconhecida universalmente.

Podemos concluir que todos os dias a ética nos convoca para o desafio dos valores morais, as mudanças obrigam a adaptações, a uma necessidade que deve ser preocupação de todas as pessoas, é um erro pensar que a ética é só para alguns. Os valores devem dominar as nossas condutas éticas, não temos outra opção. As atitudes e as normas de comportamento na vida de cada um devem assumir compromissos de responsabilização. Por vezes parece haver um esquecimento destas condutas que devem regular as nossas ações, ou então fazemos crer que são apenas exigíveis aos outros não tendo nada a ver connosco.

Na realidade, a honestidade, a seriedade obriga-nos muito mais a SER. Este SER existencial que é ser bom, ser correto consigo próprio e com os 
outros, opção por valores ético-morais e não antiéticos, mesmo que isso seja violento, mesmo que isso traga algum cansaço, em termos psicológicos e socias, tenha poucos que o acompanhem, mas seguramente capaz de lutar por objetivos, e ideais superiores, que do seu ponto de vista são os melhores, sempre o SER, menos o TER.

\section{A ÉTICA COMO EXPRESSÃO DOS DIREITOS HUMANOS}

É com a Revolução Francesa e as sucessivas declarações dos direitos humanos que a universalidade dos direitos das pessoas tem sido defendida. O artigo $1^{\circ}$ da Declaração dos Direitos Humanos (1948) refere o seguinte: "Todos os seres humanos nascem livres e iguais em dignidade e em direitos. Dotados de razão e de consciência, devem agir uns para com os outros em espírito de fraternidade".

Não é por acaso, que cada vez mais nasçam organizações, tanto nacionais como internacionais, reclamando estes direitos. Há uma pressão bastante grande destas instituições, exigindo a concretização dos direitos que as pessoas têm e zelem pelo respeito rigoroso dos acordos nacionais e internacionais no que toca aos Direitos dos Homens. As organizações interessadas em ter uma boa imagem terão de ficar sensíveis a estas exigências, sob pena de perderem aquela credibilidade de que tanto se fala atualmente.

Esta necessidade, sentida por quem de direito, não fica alheia a certos sistemas que por vezes aparecem de modo sofisticado para contrariar a prática do exercício no cumprimento destes direitos. Assim, à medida que progride a mundialização, os interesses individuais, poderíamos perguntar o que leva uma organização a desrespeitar as pessoas, a não cumprir o que a lei manda, ou seja, a não fazer caso dos direitos das pessoas, a não considerar a ética como uma obrigação. Ainda há muito caminho a percorrer até se chegar à adoção generalizada de boas práticas nas organizações, sobretudo no nosso país. Estas, no entender de Morin \& Prigogine (1998), ainda não têm como objetivo prioritário os valores ética-morais, ainda fazem pouco consumo da ética, o que interessa são os lucros, as pessoas são instrumentos de trabalho, são máquinas, isto é inaceitável nas sociedades de hoje ditas desenvolvidas.

Esta situação faz-nos ter a perceção, de leis e normas que se destinam a impor os valores ético-morais, na realidade organizacional, ainda são recheados de abusos cometidos pelo poder. Isto só mostra que a ética parece ser um bem escasso, precisando que algumas normas se imponham para assegurar os direitos das pessoas. Se a ética na relação com os direitos humanos se caracteriza pela conduta das pessoas há uma obrigação que tem de estar sempre em cima da mesa, não pode ser 
deixada ao acaso. A ética serve para regular as relações defendendo os direitos de forma objetiva não abstrata. Neste sentido espera-se que as pessoas tenham uma postura ativa baseada nos valores. É imperativo reconhecer que os direitos humanos se associam aos valores ético-morais, à deontologia, cuja fundamentação sai reforçada ao tomarmos consciência da importância que a ética assume numa organização, seja ela, lucrativa ou não.

Os direitos são essenciais à pessoa humana. $\mathrm{O}$ mundo somos nós que o fazemos, o sentido de justiça não pertence a grupos restritos, é de todos nós (Declaração Universal dos Direitos Humanos, 1948). O homem é um ser dotado de liberdade e dignidade próprias. Por isso as organizações devem valorizar o indivíduo com as suas liberdades e direitos.

Chegando a este ponto cabe-nos salientar que os direitos humanos têm como principal objetivo salvaguardar a dignidade das pessoas nas organizações. Embora as Constituições e as normas promovidas pelos Estados e pelas Organizações nacionais, europeias e mundiais, cada vez mais protejam as pessoas, a lógica ainda reflete, infelizmente, o contrário, qualquer um de nós o observa, pena que se pense de modo individual e não coletivo.

Sendo os direitos um conjunto de garantias do ser humano que tem por finalidade básica o respeito e a sua dignidade, por meio da proteção contra o arbítrio dos poderes, sejam eles estatais, superiores hierárquicos ou chefias, o estabelecimento de condições mínimas de vida e desenvolvimento da pessoa humana, tudo isto tem uma certa dose de ilusão. A prevalência de formas de opressão, exclusão, desigualdade, e outras restringem o primado dos Direitos Humanos. A Declaração Universal dos Direitos Humanos e a literatura constante que vai surgindo marcam como respeito pela legalidade da cidadania a defesa dos direitos humanos, considerados universais, efetivos, invioláveis, inalienáveis e renunciáveis. A conduta ética das organizações, na sua maioria, não reflete estas características (Rodrigues, 2004). Observamos ainda um grande débito de cidadania, democracia e direitos humanos como realidades orientadas para todos.

\section{A CONSTRUÇÃo do DISCURSO SOBRE A ÉtiCA E A ORGANIZAÇÃO}

\subsection{Exigência de uma Ética nas Organizações}

Para uma melhor compreensão destes dois campos - ética e organização - pensamos ser pertinente analisar, ainda que brevemente, o modo como a ética se foi construindo como ciência e perceber a extraordinária importância que sem dúvida a ética tem tido, no 
desempenho das relações e da competitividade das pessoas, particularmente no contexto das organizações.

Na perspetiva de Argandoña (1994, p.21) a ética é uma ciência que tem por objetivo a excelência, não uma ciência dos mínimos, pretende não só o seu próprio bem, mas o bem de todos. A ética trata de ações dignas ou indignas do homem, ações que se relacionam com a moral e que tem como fundamento os valores da sua conduta, acentuamos o que já foi dito supra.

O pensar ético move-se em torno do que é bem, do que é mal; coisas aceitáveis ou não. Todo o homem deve entender que há ações que devem ser praticadas e outras não. Dessa forma, observa-se que a ética estabelece padrões sobre o que é bom ou mau na conduta humana, na tomada de decisões, tanto a nível pessoal como organizacional.

Todas as questões colocadas com a ética, com a moral ou os valores, são do âmbito da ciência Filosófica. Aristóteles, Platão, Kant, Heidegger, e muitos outros (Banks \& Nohr, 2008, p.16,17), refletem o sentido moral das sociedades nas suas épocas. É esta capacidade reflexiva que caracteriza a ética. João Paulo Leal (apud Grácio, 1991) faz referência a Ricoeur quando afirma: "Proponho (...) reservar o termo da ética para todo o questionamento que precede a introdução da ideia de lei moral e designar por moral tudo o que, na ordem do bem e do mal, se refere a leis, normas, imperativos". Assim, e de uma forma mais concisa, diz-se que a ética é a ciência da moral; a moral representa "o que é" e a "ética" "o que deve ser".

O princípio da estima pelas pessoas é imperativo, gostemos ou não delas, ou tenham tido um comportamento inadequado connosco. Esta aproximação é a que deveria ser seguida mesmo que na realidade, em muitos casos, não seja posta em prática. Quer queiramos quer não, elas são pessoas e por isso merecedoras do nosso respeito, mesmo que não tenhamos nada a ver com as suas atitudes e as suas ações. Na perspetiva de Kant, mentir, enganar, roubar ou manipular outras pessoas são sempre comportamentos moralmente errados (citado por Banks \& Nohr, 2008). Por exemplo, mesmo que a mentira produza um bom resultado, continua a ser moralmente errado, não se devendo mentir em circunstância alguma. Nunca seria moralmente correto mentir na tentativa de fugir a dificuldades, ou tirar benefícios injustos. Isto significa que no nosso caso concreto, as organizações devem tratar os seus membros, participantes, trabalhadores cada um diferente do outro, como seres humanos que também têm objetivos, não os devem usar para alcançar os seus próprios fins, mas atuar com humanidade com os outros como gostariam que fizessem o mesmo consigo. 
Este tipo de abordagem da ética apela a uma conduta do ser humano, na escolha de valores e princípios, de modo a dar uma orientação definida ao seu comportamento, à sua relação com os outros e com a natureza em geral (Jardiller, 1986; Meynaud, 1996). Parece ser comum a todos os seres humanos a necessidade de dar um rumo coerente ao seu comportamento, elegendo os valores que lhe sirvam como guia, respondendo às suas exigências mais profundas. É evidente, perante determinada situação que não podemos tomar opções de ânimo leviano, pois exigem um compromisso consciente que envolve todas as dimensões do ser humano: racional, emotivo ou comportamental.

Neste sentido, a ética tende a enfatizar as relações entre as pessoas. Ética baseada em princípios morais que englobam não apenas direitos ou deveres individuais, mas também direitos e deveres coletivos, dando assim grande ênfase à importância das relações entre os participantes na organização

\subsection{A Ética como Fator Relacional nas Organizações}

A ética como fator relacional nas organizações abarca as questões emergentes não só das tecnologias, do profissionalismo a nível de conhecimento técnico e científico, os problemas do ambiente externo envolvente, mas também, e não menos importante, as relações entre as pessoas. Hoje em dia não chega saber fazer, é necessário saber ser, estar e saber Saber (Pereira, et al.2009, p.120).

Arménio Rego, com uma vasta literatura sobre esta temática ligada à ética dos comportamentos nas organizações, encontrou em estudos empíricos realizados em Portugal uma dimensão designada por "harmonia interpessoal" que não se encontra na grande maioria de estudos efetuados a nível internacional $(2002$, p.16). Para o autor esta dimensão compreende-se pela lenta mudança da cultura nacional. De facto, a elevada propensão para as relações sociais harmoniosas, a valorização da cooperação, a sensibilidade para comunicar de modo indireto e pouco claro, embora social é característico da cultura nas nossas organizações.

Um elemento chave é aquele que se prende com a dimensão ética nas suas implicações práticas. Para Guillén, citado por Reinaldo Dias (2008, p.179) as relações de confiança estão na capacidade dos líderes estabelecerem fortes ligações com os colaboradores, onde impere o respeito, a honestidade e a valorização como pessoa e como profissional. Numa palavra que sejam competentes no exercício das suas funções (Varela, 1995). Esta dimensão gera nos comportamentos: adesão, vontade, ação, ideias e intenções. A capacidade do líder em influenciar as relações leva os seus seguidores a aderir livremente à sua vontade, 
apoiados na confiança que poderá satisfazer as suas necessidades de bens úteis e agradáveis. Quando se age de modo parcial, não de modo claro e justo, pomos em cheque a ética e as relações pessoais nas organizações. Para que estas possam ser saudáveis é preciso confiança uns nos outros, tenham uma posição superior ou inferior.

Todo o ser humano procura acima de tudo ser feliz. Mas, ser feliz para Chanlat, 1992), designa sermos mais humanos, realizarmo-nos como pessoas, tornarmo-nos mais perfeitos, a ética indica-nos o caminho que devemos seguir para atingir esse fim. Uma conduta ética só nos traz benefícios tanto pessoais como organizacionais e as relações estabelecem a sua base. O prestígio que poderemos ter é algo que deve ser reconhecido por outros pelo exemplo da nossa conduta e não por nós próprios, nós apenas temos a nossa perceção. As motivações podem muitas vezes nortear os nossos comportamentos e contribuir para aferir da ética e da moral das nossas ações (Rego, 2000; Pereira, 1999).

Falar da ética relacional é poder falar de um campo de excelência, de coisas a executar, ou seja fazer, para nos tornarmos mais pessoas. Deste modo, acentuar comportamentos éticos implica valores, significados, a ética é o caminho do Homem para a felicidade (Sócrates, citado por Almeida, 1996, p.52).

Por conseguinte, a ética é o garante da equidade entre os elementos que constituem a organização sendo também um conjunto de princípios éticos socializadores dos seus constitutivos, é por isso que a ética deve ser entendida como um fator relacional que aproxima e cria um bem-estar entre as pessoas. O lugar da ética nas organizações justifica-se assim no plano dos direitos e deveres como referimos acima. Deste modo, a ética surge assim para garantir a dignidade humana, o respeito pela pessoa, a justiça, a liberdade, dimensões que procuram essa felicidade desejada pelo Homem. No fundo, isto só é possível atingir quando se estabelecem relações de confiança entre todos os profissionais, cada um no lugar e com o estatuto que tiver na organização.

\subsection{A Ética e a Competitividade nas Organizações}

A ética e a competitividade veem na senda do ponto anterior. À primeira vista, ética e competitividade podem parecer duas áreas conflituosas. Isso ocorre porque a ética nos lembra valores normas de conduta que visam o bem-estar pessoal e coletivo, como já vimos, mas parece que a competitividade nos conduz para a luta uns com os outros. Porém pensar deste modo quanto à ética e a competitividade é um engano. Os processos sociais de cooperação, competição, acomodação e conflito, tratados em todos os livros de introdução à sociologia geral 
confirmam-no. O termo competitividade é amplamente utilizado no seio das organizações. Competitividade que se caracteriza por competição e associando o termo a rivalidade com outras organizações. Entendido deste modo que uma organização é competitiva quando é capaz de oferecer serviços de maior qualidade do que as suas congéneres sem que para isso tome comportamentos antiéticos com os seus colaboradores.

A competitividade existe no dia-a-dia de cada um de nós, no trabalho, nos estudos, nos grupos dos quais fazemos parte, etc.. Competir significa a busca simultânea de dois ou mais indivíduos por uma vantagem, um estatuto, quando há apenas um lugar, por vezes procura-se destruir o outro com um certo cinismo. Mais grave ainda quando alguém faz pouco esforço, mas procura também impedir com estratégias pouco dignas o sucesso dos outros. O problema está no método como se atinge essa posição, é aqui que se exige a presença da ética. Assim, a competitividade está presente no trabalho, nos estudos, na carreira, etc. Nalgumas situações a competitividade, torna-se uma atividade que muitas vezes é sobrecarregada pela falta de ética das pessoas que formam a organização.

A competitividade seria ótima quando há cooperação, quando cada pessoa, cada organização se esquece do individual e pensam no coletivo, no bem comum. As teorias sociológicas, a Sociologia das Organizações e a Doutrina Social da Igreja em particular, indicam que adotar os padrões éticos de comportamento se tornou fundamental nas organizações que querem ser competitivas hoje e no futuro. A sua ausência será a sua morte. De facto, os princípios éticos são cada vez mais exigidos pelas pessoas e pelas comunidades em geral. Percebemos assim, que a competitividade pode ser positiva ou negativa em função do modo como vier praticada por nós.

Agir eticamente é ser competitivo, comprometido consigo mesmo, em sintonia com a essência da ética. Decisões e ações geram consequências que precisam ser sempre medidas, porém a ética, como bussola vai permitir um navegar mais tranquilo pela vida, com menor estresse e maiores realizações. Sendo assim, o que pode ser mais competitivo do que ser ético? (Magalhães, 2003).

Para João Leal (1996, p.7), “a competição não pode justificar o injustificável: a desumanização da nossa sociedade". Poderíamos questionar-nos: numa sociedade cada vez mais competitiva, mais individualista e desumana, que papel desempenha a ética e os valores na conciliação de interesses?

De facto, a relação entre ética e a competitividade sempre foi uma matéria delicada, mas nos dias de hoje, vivendo-se um contexto tão competitivo e concorrente entre as pessoas torna-se muitas vezes enviesada com uma certa competição agressiva, os outros são vistos como inimigos (Ghilardi, 2014, p.1,2). Mesmo com estes envolvimentos, à 
partida é possível que exista harmonia entre estes dois elementos, ética e competitividade. É nossa convicção ser possível, e também desejável, conciliar harmoniosamente ética e competitividade. As organizações que souberem adotar critérios de rigor, competência, relações internas e externas inspirando confiança contam certamente com uma vantagem competitiva saudável e menos conflituosa.

Neste sentido, a ética é indissociável de qualquer atitude de responsabilidade. Entendemos que a competitividade não nos pode separar da ética e da moral, da responsabilidade associada aos valores, dos princípios e às regras presentes na organização. A competitividade deve contribuir para o sucesso, tanto das pessoas como das organizações e não para a sua destruição.

Os princípios éticos devem ser utilizados nos diversos relacionamentos da organização com todos os que a constituem, interna e externamente. No entender de Moreira (1999) a competitividade quando ligada à ética torna-se bem mais eficiente e eficaz dentro das organizações. Não temos dúvida que essas práticas aumentam a confiabilidade nas relações tornando-se assim pontos presentes quanto à vantagem competitiva da organização.

A ética é competitividade saudável quando respeitamos os outros, é coerência de vida, é dever de cidadania, é cultura, é responsabilização e harmonia. De modo algum a ética é conflito. Teresa Guerra ao tratar deste assunto (1996: p. 8 e ss.) coloca a seguinte questão: "Numa sociedade cada vez mais competitiva, em que cada empresa procura subsistir às condições atuais de mercado e de concorrência, que papel desempenham os valores, a ética, e como se conciliam com os interesses empresariais?" As respostas não são óbvias. Numa sociedade competitiva, como é a atual, onde os interesses individuais põem em causa os coletivos, a desumanização das organizações, o papel desempenhado pelos valores e a ética na conciliação de interesses não é fácil.

As organizações são sistemas de cooperação e competição, enquanto há uma colaboração para atingir os objetivos que são comuns a todos e que constituem os fins da organização. No entanto, não podemos deixar de pensar também na competição por maiores privilégios, por promoção pessoal, para obtenção de benefícios, sem que isto seja muitas vezes feito esmagando o outro, e, por isso entram aqui os conflitos e os comportamentos antiéticos. Esta situação pode estar latente durante longos tempos e explodir em determinados momentos, principalmente quando há maiores pressões, internas e externas, contribuindo para o malestar das relações interpessoais pelo motivo dos interesses divergentes que são sempre indesejados quando se defende o bem comum como um dos maiores valores das organizações. 
Pelo exposto se percebe que pode haver momentos em que é difícil decidir-se por atitudes comportamentais éticas. Por vezes, o "eu ético" de cada pessoa entra em conflito com a organização. As relações, independentemente das competências, ou dos estatutos de cada um, há a necessidade de partilhar valores, princípios universais, dirigidos a todos, valorizando a dignidade da pessoa humana e garantindo as relações entre todos os recursos humanos na organização. Esta garantia dada pelas leis universais deve também ser legitimada com os códigos éticos de cada organização. É importante referir que, quando surgem em contexto organizacional conflitos, temos de ter uma consciência clara que a participação de todos nas soluções é a melhor maneira de defender a dignidade das pessoas no presente das organizações mas também no seu futuro

\section{OS CÓDIGOS ÉTICOS E AS ORGANIZAÇÕES}

Cada organização possui os seus próprios códigos de ética, seja ela de que tipo for, a organização estabelece regras que devem ser objetivas. Tudo deve ser conhecido, não se pode cumprir o que não se conhece, ou então limitamo-nos a generalidades que não servem a ninguém, esconder para depois se tirarem benefícios não é uma boa atitude, é desonesto, são comportamentos antiéticos que são de rejeitar. Os códigos servem para compromissos transparentes entre todos os participantes, isto é, a força de trabalho, clientes e fornecedores, conciliando o interesse de todos e valorizando o ser humano.

As exigências requeridas para a prática dos códigos não passam apenas por um bem pessoal, mas são uma arte do bem comum para todos (Kiston e Campbell, 1996, p.13). É por isso que os códigos éticos têm por base o critério do maior bem para a pessoa e para a organização como um todo.

Ora, os códigos de ética apresentam os princípios mais relevantes a serem observados, princípios que têm aplicação prática, não podem ser vistos como um conjunto de meras intenções, como princípios são inseparáveis da identidade da atividade e da responsabilidade social.

$\mathrm{Na}$ maior parte das organizações justifica-se a tendência para desenvolver e encorajar ações de acordo com princípios éticos, não só por ser moralmente correto, mas também porque a curto prazo poderá tornarse numa vantagem competitiva. Esta vantagem traduz-se numa imagem da organização para as outras organizações e para a sociedade em geral.

Para que princípios e padrões éticos sejam cumpridos por todos os colaboradores da organização torna-se imprescindível que os mesmos compreendam em pleno o conteúdo do código de ética, ou seja, as regras e procedimentos que definem a cultura da organização. 
Embora os códigos se baseiem em princípios e valores, há alguns aspetos a termos em conta: Os dados conhecidos referem que na prática não se podem transferir modelos organizacionais totalmente distintos de outras culturas, pois o sucesso nalguns países pode ser o fracasso noutros. Deste modo, há razões para que gestores, diretores, chefes das organizações considerem as particularidades, tendo cuidado nos estilos de liderança, no modo como comunicam com os seus colaboradores, como procuram motivá-los e como premeiam o seu trabalho.

Justifica-se o recurso a códigos de ética, adaptados a cada organização. Embora em termos gerais os princípios sejam os mesmos há especificidades que os responsáveis necessitam considerar, uma vez que as coisas não são tão lineares, os dados teóricos devem ser usados com prudência e não generalizações que têm pouca aplicabilidade nas ciências sociais, o mesmo se passa nesta análise, não existe uma certeza igual para todas.

Por isso, a ética nas organizações não é uma questão de conveniência (Arruda, 2003), é sim uma condição necessária para a sua sobrevivência. O comportamento ético por parte das organizações é esperado pelos seus constituintes e pela sociedade. Isto é, impõe-se que a organização tenha uma conduta ética com os trabalhadores, clientes, fornecedores, competidores, público em geral, por isso são importantes os códigos.

Julgamos as organizações e os seus responsáveis pelas suas ações, não por piedosas declarações de intenções (Adrian Cadbury citado por Moreira, 1996a).

Para impedirem comportamentos antiéticos ou más condutas por parte dos seus colaboradores, a administração de uma organização deve estabelecer critérios uniformes, princípios e valores que reflitam a cultura da organização, através da criação de um código de ética. Este código para além de uniformizar critérios, serve de parâmetro para a solução de conflitos.

São muitos os benefícios e a formalização dos códigos de ética nas organizações. São instrumentos através dos quais a organização estabelece certos objetivos de índole ético que deseja alcançar, dentro e fora da mesma. Neste sentido, os códigos éticos têm como função servir de guia a situações ambíguas, oferecer proteção e defesa, melhorar a reputação, o desempenho e o comportamento dos trabalhadores (felicidade, honestidade). Os códigos permitem criar um clima de trabalho favorável a todos, regulamentam estratégias para evitar erros em matéria de ética; são catalisadores das mudanças na organização; incentivam comportamentos positivos, ajudam a satisfazer as necessidades dos investidores, a proteger os dirigentes dos seus subordinados e vice-versa. Isto é óbvio, ninguém dúvida do valor que os 
códigos têm e quanto são úteis para a clareza e afirmação de cada organização.

Porém, a introdução de um código ético pode ser também um delicado processo com efeitos perversos como indica Moreira (1996b). Isto acontece porque o moral (ou ético), em termos da nossa cultura ainda continua a ser algo que está "fora do económico", faz parte de uma competência das instituições religiosas ou da consciência individual. Isto explica que ainda hoje o mundo dos negócios, das atividades organizacionais, seja visto com sendo pouco moral (Idem).

De facto, criar um código de ética implica uma certa rotura com uma visão ainda muito fechada em relação à cultura organizacional, o que não é de estranhar existirem ainda algumas resistências ao processo de introdução de um código ético nas nossas organizações.

Ao incluirmos neste artigo este ponto pode resumir-se a alguns princípios de particular interesse. Antes de tudo, a obrigação que as organizações têm de ajudar ao desenvolvimento humano e profissional dos seus membros, mas também, uma organização que pretenda ter bons profissionais não pode de modo algum prescindir da moral nem dos valores éticos. Mesmo que os objetivos das pessoas e das organizações sejam distintos, as suas atuações têm de ter apenas um sentido, aquele da comunidade porque interessam a todos.

Deste modo, os códigos de ética têm como função principal regular conflitos de interesses e proporcionar um ambiente estável, onde a boa conduta salvaguarde os interesses comuns. Assim, a organização deve dar lugar a valores que inspirem a sua ação do ponto de vista não só técnico, económico e social, mas e sobretudo, incluir valores humanos básicos, dando sentido à dignidade humana fazendo face ao bem comum, valor que supera o bem individual como já temos vindo a afirmar ao longo deste texto.

Mas, como indica Moreira (1996a, p.4) "pôr em andamento um código ético deve traduzir-se numa elevação da excelência, em especial num aumento dos requisitos dos padrões de comportamento dos diretivos. O seu exemplo é o primeiro requisito para dar coerência ao processo". Isto significa que os comportamentos devem conjugar esforços mesmo quando os objetivos são difíceis de atingir. Os dirigentes devem assumir os compromissos e fazer corresponder as suas condutas com os códigos que eles próprios elaboraram.

O conhecimento e cumprimento dos princípios constantes no código de ética devem ser da responsabilidade de todos os membros da organização, mas com destaque para quem a gere e tem maiores responsabilidades. Assim os critérios de punição devem estar devidamente identificados no código de ética (Ibidem, p.186). Ora para que os códigos sejam eficientes é imperativo a existência de canais de 
comunicação também eficientes (Gibson, et al. (2000, p.99; Moreira, 1999, p.194). Estes canais são fulcrais para a ética no grupo. Através dos canais de comunicação poderão ser dissipadas dúvidas sobre ética ou denunciadas violações de comportamentos menos éticos.

Porém, a simples existência de um código de ética não garante em absoluto que o comportamento dos membros das organizações seja sempre correto, mas ajuda a clarificar expetativas e aperfeiçoar atitudes comportamentais, chamando a atenção para os valores vigentes no seio das organizações.

Como já nos referimos supra, os compromissos com o código de conduta ética acentuam-se à medida que as pessoas se encontram na hierarquia, desde o topo à base, manifesta-se com as suas ações e sobretudo com o seu exemplo, uma figura reconhecida e independente, que atue com lealdade para com a organização, com justiça e honestidade com todos os seus membros. Numa palavra, que atue como defende a moral e a ética no grupo onde opera respeitando e praticando os valores pessoais e da organização através da responsabilidade, independência, profissionalismo, compromisso e integridade, como critérios essenciais. Neste âmbito, cabe às administrações responsabilidades suplementares, o seu exemplo é essencial, assim como estar disponível para os colaboradores que pretendam estabelecer dúvidas ou eventuais atitudes que os desgostam.

Por conseguinte, as organizações devem-se responsabilizar pelo desenvolvimento de um programa de ética se quiserem incentivar o comportamento ético. Embora não solucionem todos os problemas, ajudam a impedir comportamentos negativos e inaceitáveis em contexto organizacional. Códigos claros, completos, honestos e justos, porque são instrumentos relevantes para os comportamentos e ações desenvolvidas na organização.

Finalmente, não podíamos deixar de considerar que os códigos de ética se devem sempre nortear pelos princípios da legalidade e da moralidade. De facto o desempenho correto e eficaz de uma organização depende em certa medida da capacidade de cada um dos seus agentes na aplicação da lei. Esta observação indica que ninguém será obrigado a fazer ou deixar de fazer alguma coisa senão em virtude da lei.

Assim, os responsáveis devem cumprir as leis de modo correto, pois a aplicação da lei não pode estar baseada em práticas ilegais, de modo arbitrário, estas práticas conduzem à desconfiança entre as chefias e os trabalhadores e transmitem uma imagem negativa da organização.

A organização deve assegurar a igualdade de todos perante a lei, para que todos tenham as mesmas oportunidades. É por isso que as práticas na aplicação dos códigos devem estar em conformidade com os princípios da 
legalidade. Deste modo, nem condições excecionais nem ordens de superiores podem justificar comportamentos ilegais. É importante que os códigos de ética estejam de acordo com as normas legais e morais tanto na sua elaboração como na sua aplicação. Estas preocupações devem estar presentes em todos evitando possíveis problemas futuros.

\section{CONSIDERAÇÕES FINAIS}

A ética está, como vimos, diretamente relacionada com a vida das organizações. De facto a prática da ética é, do nosso ponto de vista, o caminho certo a ser seguido por aquelas que aspiram ao sucesso e procuram transmitir uma imagem saudável nas relações que estabelecem.

Das muitas leituras e da análise que fizemos torna-se fácil tirarmos algumas conclusões. De facto, as organizações além de estarem atentas às suas responsabilidades económicas, também precisam estar atentas às suas responsabilidades éticas, morais e sociais (Ashley, 2002). É fundamental a prática dos princípios éticos, as organizações são construídas pelas pessoas no seu interior, mas são feitas também com a sociedade, conduzindo a uma construção mais justa e feliz. É por isso que a ética é infinita nas palavras de Levinas (1982).

As organizações reconhecidas como éticas, e socialmente responsáveis, gozam de um ambiente interno e externo de maior confiança, proporcionam uma grande estabilidade, identifica-se com os princípios e valores que descrevemos, resultando em benefícios efetivos que são visíveis e reconhecidos por todos. Por outro lado, a ética nas organizações é também um fator importantíssimo para a sobrevivência das mesmas. Quanto maior consciência pelas organizações em relação à importância da ética na sua vida e quanto melhor for aplicada, mais reverterá para o benefício de um maior número de pessoas.

Por isso não nos surpreende que atitudes e comportamentos antiéticos ponham em jogo não só a qualidade, mas também uma sobrevivência sem moral, sem valores, sem ética, contribuindo assim para a instabilidade das pessoas e das organizações.

Acresce ainda também, afirmar que é ético poder escolher livremente, eleger o bem e não o mal. A fonte da ética é a própria realidade humana, o ambiente em que vivemos. Assim, o ambiente de trabalho, no qual passamos grande parte do nosso dia, desenvolve-se numa sucessão de escolhas e de prática de virtudes, que nada mais são que os valores éticos transformados em ação.

Resumindo a ética é uma ciência prática, que para além dos princípios teóricos, exige uma aplicação prática. Como evidencia Moreira (1996a) não se estuda para saber, mas estuda-se para atuar. $O$ verdadeiro significado da ética numa organização é ajudar à excelência das pessoas. 
Nunca ninguém se tornou ético assistindo a seminários ou cursos de ética, como refere Moreira, se assim fosse, as pessoas de pouca cultura teriam todos comportamentos antiéticos, pelo contrário, são os mais instruídos que efetivamente têm condutas menos éticas (Idem). A ética é algo que se pratica de forma continuada, não apenas quando se verificam condições favoráveis, pois o difícil é quando temos o contrário.

Em suma, perante a análise realizada neste artigo sobre a ética em contexto organizacional, certamente, que o tema não fica esgotado, mas pode ser um contributo na identificação do muito que há a fazer para que a ética seja um instrumento que possa conduzir a práticas corretas, ressalvando, no entanto, que a ética é subjetiva e passível de interpretações diferentes. Desta forma, a interpretação da ética, evidenciada por Hessen (2001, p. 201) vem relacionada com a moral pois afirma: "perante esta realidade servirá porventura a consciência moral de cada um, pois torna-se a verdadeira pátria dos valores éticos". Valores de justiça, de honra, de verdade e de transparência nos comportamentos das organizações.

\section{REFERÊNCIAS BIBLIOGRÁFICAS}

Amblard, H. (1996). Les nouvelles approaches sociologique des organizations, Paris: Seuil.

Almeida, F. N. (1996). Sucesso pessoal a quanto obrigas? Separata da Revista Dirigir (45), Lisboa: IEFP, 51-53.

Argandoña, A. R. (1994). La ética en la empresa, Madrid: Instituto de Estudos Económicos.

Arruda, M. C. C. (2003). Fundamentos de ética empresarial e económica ( $2^{\mathrm{a}}$ ed.), São Paulo: Atlas.

Ashley, P. A. (2002). Ética e responsabilidade social, São Paulo: Saraiva. Assembleia, G. N. U. (1949). Declaração Universal dos Direitos Humanos. Acedido a 3 de fevereiro de 2014. Disponível em http://portal.mj.gov.br/sedh/ct/legisl_intern/ddh_bib_inter_.

Banks, S. \& Nohr, K. (coords) (2008). Ética prática para as profissões do trabalho social, Porto: Porto Editora Lda.

Bilhim, J. (1996). Teoria organizacional: Estruturas e pessoas, Lisboa: Instituto Superior de Ciências Sociais e Políticas (ISCSP).

Blanchard, K. \& Peace N. V. (1989). O poder da gestão ética, Lisboa: Difusão Cultural.

Brugger, W. (1969). Ética. Dicionário de Filosofia, São Paulo: Herder.

Chanlat, J. F. (1992). A caminho de uma nova ética das relações nas organizações. Revista da Administração de Empresas, vol. 32 (3), 68-73. 
Cabral, R. (2000). Temas de ética, Braga: UCP:

Decio, Z. (2002). Organização Ética: um ensaio sobre comportamento e estrutura das organizações. Acedido a 2 de fevereiro de 2014. Disponível em http://www.scielo. br/pd/rac/v6n2/v6n2a 08. pdf.

Dias, M. O. (2004). Reflexões sobre a ética no quotidiano da profissão. Gestão e Desenvolvimento (12), Viseu: UCP, 81-103.

Dias, R. (2008). Sociologia das organizações. Acedido a 11 de fevereiro de 2014. Disponível em vejasociologia.blogspot.com/p/introduçãoao-estudo-sociologico-das.html.

Etzioni, A. (1984). Organizações modernas (2a ed.), S. Paulo: Livraria Pioneira Editora.

Ferreira, M. M. \& Dias, M. O. (2005). Ética e profissão Relacionamento interpessoal em enfermagem, Loures: Lusociência.

Gibson, J. L. et al. (2000). Administração, Amadora: McGraw-Hill.

Gil, M. L. \& Delgado, L. (1996). De camino a una ética empresarial, Buenos Aires: Biblos.

Guedes, R. (2009). Organizações: conceito e classificações. Acedido a 31 de janeiro de 2014. Disponível em http://www.admronaldoguedes.com

Guerra, M. J. T. (1996). Ética e competitividade: conflito ou harmonia? Separata da Revista Dirigir (45), Lisboa: IEFP, 8-10.

Ghilard, J. A. (2014). A competitividade e a ética. Acedido a 14 de fevereiro de 2014.2 Disponível htt://www.maua.br/arquivos/artigo/h/78b4124d6ec9912b338ea8fba4 $469 \mathrm{ef3}$.

Hessen, J. (2001). Filosofia dos valores, Coimbra: Almedina.

Jardiller, P. (1986). Le développement humain dans lenterprise, Paris: PUF.

Leal, J. P. F. (1996). Ética empresarial. Dirigir, Lisboa: IEFP, p.3-5. Apud Grácio, C. (1991). Ética, Dicionário do pensamento contemporâneo, Lisboa: Círculo de Leitores.

Leite, A. P. (julho/setembro, 2003). A globalização o desenvolvimento e a ética. Nova Cidadania, ano V (17), Lisboa: Quetzel Editores.

Levinas, E. (1982). Éthique et infinit, Paris: Arthémme Fayard.

Kenneth, B. \& Peaple, N. V. (1993). O poder da ética, Lisboa: Difusão Cultural.

Kitson, A. \& Campbell, R. (1996). The etical organisation, London: MacMillan.

Magalhães, D. (2003). Ética e competitividade. Acedido a 11 de fevereiro de $2014 . \quad$ Disponível em http://www.dulcemagalhaes.com.br/artigos/11-2003/76-etica.

Marttini, C. M. (1993). Viaggio nel vocabolario dell etica, Milano: Piemme SPA. 
Meynaud, H.Y. (org.) (1996). Les enjeux éthiques dans les organizations moderns. Les sciences socials et l'enterprise, Paris: D’ecouvert, 336-357.

Moreira, J. M. (1996a). Ética, economia e política, Porto: Lello \& Irmãos Editores.

Moreira, J. M. (1996b). Liberalismo: entre o conservadorismo e o socialismo, Lisboa: Pedro Ferreira.

Moreira, J. M. (1999). A ética empresarial. Acedido em 11 fevereiro de 2014.

Disponível

em http://www.eticaempresarial.com.br/index1.htm.

Morin, E. \& Prigogine, I. (1998). A sociedade em busca de valores, Lisboa: Instituto Piaget.

Nunes, P. (2007). Conceito de organização. Acedido a 1 de fevereiro de 2014. Disponível em http://www.notapositiva.com/trabprofessores/textos-apoi.

Pereira, O. (1999). Fundamentos de comportamento organizacional, Lisboa: Fundação Calouste Gulbenkian.

Pereira, C.A.A. et al. (2009). Importância da ética para a prática e para a ciência. Revista Portuguesa de Bioética, (8), 187-197.

Pinto, J. R. C. (1990). Questões actuais da ética (3 $3^{\mathrm{a}}$ ed.), Braga: A.O.

Rego, A. (2002). Comportamentos de cidadania nas organizações - um passo na senda da excelência? Lisboa: McGraw-Hill.

Rego, A. (2000). Comportamentos de cidadania organizacional diferentes padrões reactivos às percepções de justiça. Organização $e$ Trabalho, (24), 9-28.

Rego, A. Moreira, J. M. \& Sarrico, C. (2003). Gestão ética e responsabilidade social das empresas, S. João do Estoril: Principia.

Rodrigues, E. F. (2004). Cidadania e democracia: Uma realidade para todos. Acedido a 10 de fevereiro de 2014. Disponível em http://www.iedc.org.br/publica/500anos/flávia.htm

Significados (sd). Acedido a 1 de fevereiro de 2014. Disponível em http://www. Significados.com.br/organização.

Teixeira, S. (1998). Gestão das organizações, Amadora: McGraw-Hill.

Trigo, J. (1999). Ética. Enciclopédia Luso Brasileira de Cultura, Vol. XI (Edição Século XXI), Lisboa/São Paulo: Editorial Verbo, 225-268.

Varela, F. (1995). Sobre a competência ética, Lisboa: Edições 70. 